3 Xu Tian ${ }^{\mathrm{a}, \mathrm{b}}$, Hancheng Dai ${ }^{\mathrm{c}}$, Yong Geng ${ }^{\mathrm{a}, \mathrm{d}, \mathrm{e}^{*}}$, Shaohui Zhang ${ }^{\mathrm{f}, \mathrm{g}}$, Yang Xie ${ }^{\mathrm{f} *}$, Xiaorui Liu ${ }^{\mathrm{c}}$,

$4 \quad$ Pantao $\mathrm{Lu}^{\mathrm{c}}$, Raimund Bleischwitz $\mathrm{b}^{\mathrm{b}^{*}}$

$5 \quad{ }^{\text {a }}$ School of International and Public Affairs, Shanghai Jiao Tong University, Shanghai

$6 \quad 200030$, China

$7 \quad{ }^{\mathrm{b}}$ Institute for Sustainable Resources, Bartlett School of Environment, Energy and

8 Resources, University College London, Central House, 14 Upper Woburn Place,

9 London WC1H 0NN, United Kingdom

\section{Toward the 2-degree target: evaluating co-benefits of road} transportation in China

c College of Environmental Sciences and Engineering, Peking University, No.5 Yiheyuan Road, Beijing, 100871, China

d China Institute of Urban Governance, Shanghai Jiao Tong University, No. 1954, Huashan Road, Shanghai, 200030, China

e Shanghai Institute of Pollution Control and Ecological Security, Shanghai 200092, P. R. China

${ }^{\mathrm{f}}$ School of Economics and Management, Beihang University, Beijing 100191, China g International Institute for Applied Systems Analysis, Schlossplatz 1, A-2361 Laxenburg, Austria

\section{Corresponding Author}

*Yong Geng; Email: ygeng@sjtu.edu.cn; Tel: +86-21-54748019; Fax: +86-2154740825. School of Environmental Science and Engineering, Shanghai Jiao Tong University, Shanghai 200240, China 
23 *Yang Xie; Email: xieyangdaisy@buaa.edu.cn, Tel : +86-01-82317832, School of 24 Economics and Management, Beihang University, Beijing, 100191, China

25 *Raimund Bleischwitz; Email: r.bleischwitz@ucl.ac.uk; Institute for Sustainable 26 Resources, Bartlett School of Environment, Energy and Resources, University College 27 London, Central House, 14 Upper Woburn Place, London WC1H 0NN, United 28 Kingdom 


\section{Toward the 2-degree target: the role of road transport sector in China}

\section{Structured Abstract}

Background: Co-benefit assessments on health and economic impacts of climate change mitigation towards the 2-degree target are lacking, especially from a sectoral perspective.

Objectives: This study aims to (1) evaluate PM2.5 pollution-related health impacts on China's road transport sector at both national and provincial levels toward the 2-degree target by 2050; (2) uncover the contribution from the road transport sector compared with that of all sectors; (3) distinguish the contribution from climate change mitigation actions compared with air pollution control oriented actions in road transport sector; and (4) identify the heterogeneous influences at provincial level.

Methods: Health and economic impacts are estimated using an integrated approach that combines the GAINS (Greenhouse Gas and Air Pollution Interactions and Synergies) model, the IMED/CGE (Integrated Model of Energy, Environment and Economy for Sustainable Development/computable general equilibrium) model and IMED/HEL (Health) model. Five scenarios are proposed based on climate change mitigation and stringency of air pollution control policy.

Results: China's road transport sector could contribute to around 10.6\% of total PM2.5 concentration reduction, equivalent to $10.8 \%$ of the monetized health benefits obtained from achieving the 2-degree target by all sectors. Populous provinces with more 
manufacturing industries would benefit more. Meanwhile, climate change mitigation action alone can lead to $70 \%$ reduction of health impacts by applying air pollution control measures .

Conclusions: This research has implications for other emerging economies and those reluctant to engage in climate action. Government should adopt a more flexible policy approach to take into account regional pollution levels and abatement options.

Key Words: 2-degree target; co-benefits; public health; air pollution; China; Governance

\section{Introduction}

In order to build up a low carbon future, the Paris Agreement set the 'well below 2degree target' for strengthening the global response to the threat of climate change (UNFCCC, 2018). This ambitious target leads to manifold questions over trade-offs and synergies related to abatement strategies. Although many countries pledged to combat climate change via nationally determined contributions (NDCs), the implications such as co-benefits and trade-offs toward a 2-degree target are not fully explored and still have a lot of uncertainty (Hanaoka et al., 2017). The related uncertainty would further challenge those policymakers and affect the achievement of the 2-degree target.

As the world's largest carbon emitter, China has made great efforts on responding to climate change. Pledging that by around 2030, China would lower carbon dioxide emissions per unit of GDP (Gross Domestic Product) by $60 \%$ to $65 \%$ from the 2005 level (UNFCCC, 2018). In addition, China is facing severe challenges in treating air 
pollution. China's outdoor air pollution caused more deaths with high concentrations of fine particulate matter pollutant $\left(\mathrm{PM}_{2.5}\right)$ than in any other countries (Lelieveld et al., 2015; Meng et al., 2015; Cai et al., 2017; Lanzi et al., 2018). Therefore, the analysis of co-benefits related to climate change mitigation and health problems caused by air pollutants is crucial for China. In particular, it is necessary to investigate the co-benefits between carbon emission reduction and air pollutants for China as a whole, as well as across different Chinese provinces.

In order to achieve such a research goal, methodological assessment challenges need to be addressed. Previous studies show that climate change mitigation could bring co-benefits to the improvement of air quality, mainly from climate policy (Liu et al., 2014; Dong et al., 2015), air pollution regulation (Nam et al., 2013; Li et al., 2017), energy policy (Peng et al., 2018), economic instruments (Mao et al., 2012) and consumer behaviors (Liang et al., 2016). In terms of air pollutants reduction, previous studies have found that climate change mitigation could bring the co-benefits to offset the related health issues and economic impacts. For instance, Peng et al., (2018) found that half decarbonized power supply ( $\sim 50 \%$ coal) for electrification of the transport and/or residential sectors leads to a $14-16 \%$ reduction in carbon emissions and air quality and health co-benefits (55,000-69,000 avoided deaths in China annually) than coal intensive electrification in 2030. Xie et al., (2018) estimate that the climate change mitigation could reduce premature deaths in Asia by 0.79 million by 2050, which is equivalent to a life value savings of approximately 2.8 trillion USD. Although such previous studies identified the co-benefits between climate change mitigation and air 
pollutants reduction (He et al., 2010; Takeshita, 2012; Dong et al., 2014; Dong et al., 2015; Liang et al., 2016), a comprehensive study that assesses co-benefit of the 2degree target is still lacking. In addition, there are few studies focusing on the economic impacts of one certain sector, especially the major sectors that contribute to ambient air pollution. Therefore, it is important to initiate such studies for preparing national policies on both climate actions and public health, and in particular for the wider debates on economic impacts (Hanaoka et al., 2017; Wu et al., 2017; Watts et al., 2018; Xie et al., 2018).

Road transport is a key sector, as it is critical to both economic development and environmental protection. It is reported that road transport has the largest effect on global warming (Berntsen et al., 2008). In addition, road transport accounts for $18.4 \%$ of total PM emissions worldwide (Xia et al., 2015). Long-term exposure to trafficrelated air pollution is associated with increased mortality from respiratory and cardiovascular diseases and lung cancer, which shortens life expectancy (Künzli et al., 2000; Zhang et al., 2017). For China, carbon emissions from China's transport sector accounted for $10 \%$ of the overall emissions in 2012 , contributing to the largest portion in the whole transport sector (Dai et al., 2017). Furthermore, it is predicted that rapid growth of road transportation in China would likely continue in the next two to three decades (Yan et al., 2010). In addition, He et al., (2016) found that air pollution from the road transport sector in China has led to substantial increases in the risk of lung cancer, respiratory and cardiovascular diseases. Although several studies explored the health impacts of air pollution from the transport sector (Pan et al., 2016; Liu et al., 
2018), few studies estimated the associated health and economic benefits, especially in China (Tian et al., 2018). In addition, given the provincial heterogeneity of air quality and socio-economic conditions, the health impacts would be region-specific across the whole country. However, to the best of our knowledge, the co-benefits impact of China's road transport sector toward the 2-degree target on human's health and regional economy at the provincial level in China have not been investigated. Consequently, it is critical to initiate such a study so that valuable policy insights can be provided to the Chinese decision-makers, which might also be valuable to other countries with similar challenges.

Under such circumstances, this study aims to uncover both health and economic impacts caused by $\mathrm{PM}_{2.5}$ pollution from the road transport sector in 30 Chinese provinces toward the 2-degree target, to answer three questions: (1) Identifying the role and co-benefits of China's road transport sector toward the 2-degree target at national and provincial levels (2) Exploring the differences in health and economic impacts of climate change mitigation toward the 2-degree target at provincial level (3) Assessing co-benefits in terms of health and air quality improvement brought by climate change mitigation, compared with the maximum benefits resulting from technology upgrade. This study adopts an integrated approach, which closes the economy-environmenthealth loop by combining an air quality assessment model, an economic model, and a health assessment model so that the complex interactions between the environment, public health, and economic aspects can be uncovered. 


\section{Methods}

This study integrates three models, including the GAINS (Greenhouse Gas and Air Pollution Interactions and Synergies) model, the IMED/HEL (Integrated Model of Energy, Environment and Economy for Sustainable Development/health) model and the IMED/CGE (Computable General Equilibrium) model, to identify the health and economic impacts of $\mathrm{PM}_{2.5}$ pollution from the road transport sector at the national and provincial levels in China toward 2-degree target. Both IMED models are developed by the Laboratory of Energy \& Environmental Economics and Policy (LEEEP) at Peking University. All three models cover 30 Chinese provinces except for Tibet, Hong Kong, Macau and Taiwan. Figure 1 shows the interactions between these models. In this study, emissions such as $\mathrm{NO}_{\mathrm{X}}, \mathrm{SO}_{2}, \mathrm{PM}_{2.5}$ and $\mathrm{CO}_{2}$ are from the GAINS model. Health impacts such as annual mortality, risk of morbidity and work time loss caused by $\mathrm{PM}_{2.5}$ pollutions are identified via the IMED/HEL model. After combining IMED/HEL and IMED/CGE models, economic impacts such as extra health care expenditures and the maximized embodied economic value (MEEV) based on the values of statistical life are presented in our current study. The technical introduction on the IMED model framework, including the IMED/CGE and IMED/HEL models, is available at http://scholar.pku.edu.cn/hanchengdai/imed_general.

Ffive scenarios are established based on various climate change mitigation and air pollution control policies. Table 1 shows the details of these five scenarios. 


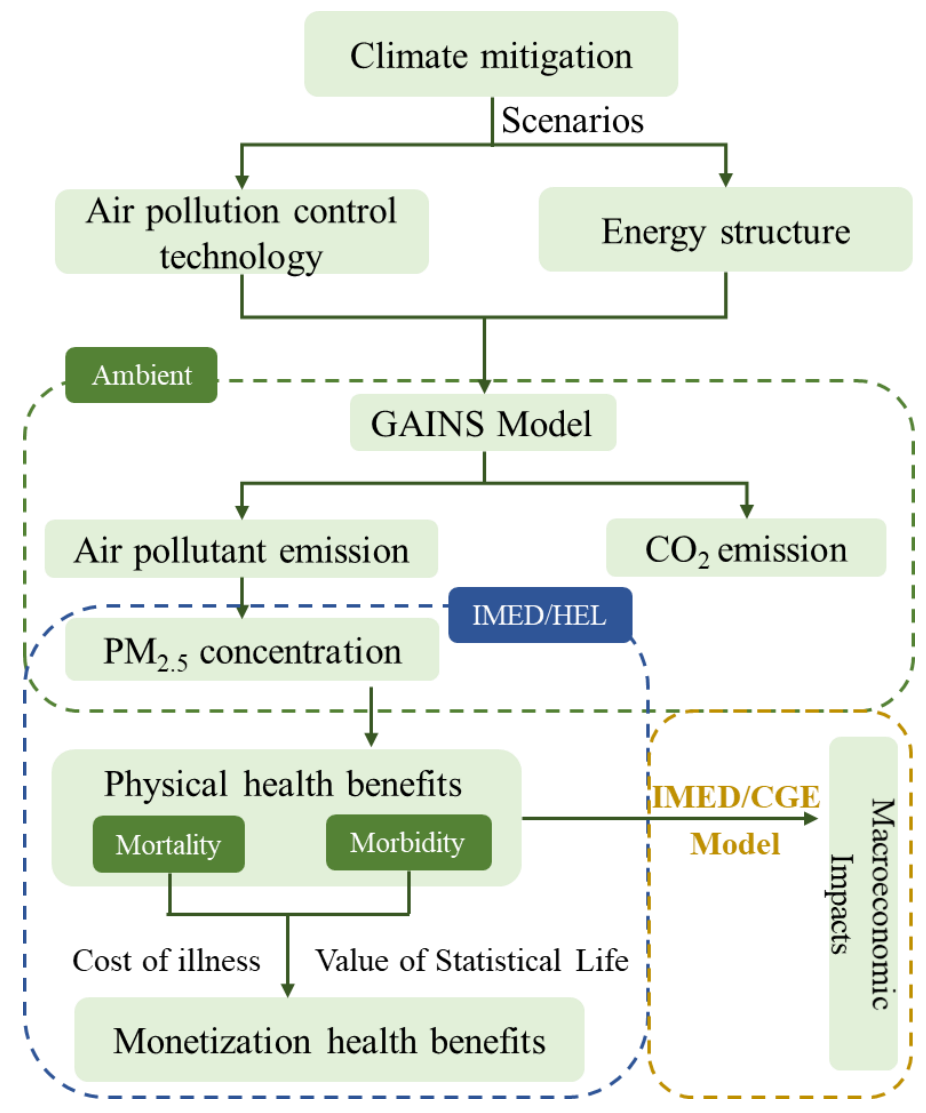

Figure 1. Research framework

Table 1. Explanations of five scenarios

\begin{tabular}{|c|c|c|c|}
\hline Scenario & Health impact & $\begin{array}{l}\text { Climate change } \\
\text { mitigation measure }\end{array}$ & Air pollution control measure \\
\hline BaU & Ignored & None & None \\
\hline REF & Not ignored & None & Current legislation without additional control \\
\hline 2DEG_all & Not ignored & $\begin{array}{l}\text { 2-degree standard in all } \\
\text { sectors }\end{array}$ & Current legislation without additional control \\
\hline 2DEG_RT & Not ignored & $\begin{array}{l}\text { 2-degree standard in road } \\
\text { transport sector only }\end{array}$ & Current legislation without additional control \\
\hline TECH & Not ignored & None & Strict additional control \\
\hline
\end{tabular}

168 which assumes that the health impacts from $\mathrm{PM}_{2.5}$ pollution are ignored. Although this

169 scenario simulates an ideal situation that does not exist in reality, it can be used to evaluate the negative macroeconomic impacts of pollution and benefits by comparing 
with other scenarios. The other four scenarios consider the health impacts caused by $\mathrm{PM}_{2.5}$ pollution.

REF scenario assumes that except for the current legislations, no additional air pollution controls are applied in the GAINS model.

2DEG_all scenario assumes all sectors will take actions toward achieving 2-degree scenario, implying that the total energy consumption of China is in line with the decarbonization scenario in the International Energy Agency (IEA) report, which has the objective of limiting the average global temperature increase in 2100 to 2 degrees Celsius above pre-industrial levels (IEA, 2016).

2DEG_RT scenario assumes that only the road transport sector will take action to achieve the 2-degree target. Energy consumption of transport sector will be in line with the 450 scenario in IEA report whereas that of other sectors will be in line with the REF scenario. After comparing 2DEG_all scenario and 2DEG_RT scenario, the contribution of the road transport sector in all sectors can be assessed.

The TECH scenario assumes strict air pollution controls associated with fuel standards and vehicle technology standards will be implemented beyond the current legislations. By comparing the REF scenario with both 2DEG_RT and TECH scenarios, the health and economic impacts of the different control measures can be quantified. Furthermore, after comparing the above impacts from 2DEG_RT and TECH scenarios, co-benefits can be evaluated in terms of climate change mitigation.

\subsection{Modelling the emissions and $\mathbf{P M}_{2.5}$ concentration scenarios}


The GAINS-China model is applied for estimating air-pollutants and $\mathrm{PM}_{2.5}$ concentration from the road transport sector in 30 Chinese provinces. It allows for a comprehensive and integrated analysis on air pollution and climate change mitigation strategies, which generats important synergies and trade-offs between these policies. GAINS quantifies technical and economic interactions between mitigation measures for the considered air pollutants and greenhouse gases (Amann et al., 2008). The basic principle of calculating emissions is presented in Equation 1.

$$
\text { Emissions }=\sum_{i} \text { Activity }_{i} \times F \times(1-r) \times C
$$

Where, $F$ (emission factors of activities), $r$ (removal efficiencies of control technologies), $C$ (control technologies) for each activity are specified in control strategies.

We set up the REF scenario, assuming that no climate policies and air mitigation technology measures are applied in the GAINS model.

Two climate control scenarios toward 2-degree target (2DEG_all and 2DEG_RT) were also set up in this GAINS model. 2DEG_all scenario assumes that all sectors will take actions toward the 2-degree target. All the parameters in this scenario are from the WEO2016_450 scenario in the GAINS model, which keeps consistent with the decarbonization scenario in the IEA report. The major character of energy consumption in China's 2-degree scenario is that electricity dominates the total final energy consumption, following by oil. In particular, different sectors have different energy consumption features. For instance, energy consumption in the transport sector is mainly driven by oil and electricity, while energy consumption in the building sector is 
mainly driven by electricity and bioenergy.

Under the 2DEG_RT scenario, the pathway of China's road transport sector is changed in the GAINS model according to the energy consumption of IEA report under China's 2-degree scenario. The major character of China's 2-degree scenario is that although oil is still the most important energy source, the proportion of electricity, natural gas and biofuels will increase significantly in the future.

Strict air mitigation technology measure implemented in road transport sector is presented by the TECH scenario in the GAINS model. Control strategy for road transport sources and control strategy for $\mathrm{SO}_{2}$ are changed according to the fuel standards and vehicle technology standards. Fuel standards mainly include natural gas, gasoline, biofuels, electricity, etc. Vehicle technology standards are from low to high with different types of vehicles, such as the EURO 1-6 on light duty spark ignition road vehicles. The setting of this TECH scenario is kept consistent with our previous study (Tian et al., 2018). In our current study, we assume that each province would apply the strictest standards for road vehicles in 2050 based on the implementation of new vehicle emission standards in China. Take China's light vehicle-VI emission standard as an example, this standard would be implemented in different provinces in late 2019 or 2020. This standard stipulates the emission limits and measurement methods of exhaust pollutants, actual driving exhaust pollutants, crankcase pollutants, evaporative pollutants, and refueling pollutants of light vehicles at normal temperature and low temperature, and pollution control devices. It also includes technical requirements and measurement methods for on-board diagnostics (OBD) systems. Two emission limit 
schemes exist, namely, VI-a and VI-b. VI-b is stricter than the EURO VI standard. by considering these conditions, we assume that all road transport vehicles will follow the strictest emission standard in 2050.

Based on the detailed spatial and sectoral GAINS emissions inventory, GAINS computes ambient concentrations of $\mathrm{PM}_{2.5}$ with the help of source-receptor relationships derived from an atmospheric chemistry-transport model (the TM5 model) (Amann et al., 2008). By comparing the REF scenario with 2DEG_all/2DEG_RT/TECH scenarios, the emissions and $\mathrm{PM}_{2.5}$ concentrations of the different control measures can be quantified.

\subsection{Modelling health impacts}

The IMED/HEL model is used to quantify the health impacts of $\mathrm{PM}_{2.5}$ concentration on six morbidity endpoints (respiratory hospital admissions, cerebrovascular hospital admission, cardiovascular hospital admissions, chronic bronchitis, asthma attacks, respiratory symptoms days), the chronic mortality and the work-loss day. The advantage of this model is that both linear and non-linear exposure-response functions (ERFs) with concentration level are identified. The function of our health model is to quantify the health burden from air pollution and the benefits of air pollution control policy. The health burden mainly includes health expenditure on air pollution-related diseases and worktime loss of air pollution-related mortality and morbidity. Using this health model, medical expenditure and the value of statistical life (VSL) loss caused by $\mathrm{PM}_{2.5}$ pollution could be estimated. In this study, the settings of IMED/HEL model refer 
to our previous studies (Xie et al., 2016; Wu et al., 2017; Tian et al., 2018). After this,

260 the health impacts from different scenarios are quantified and compared.

\subsection{Modelling economic impacts}

The IMED/CGE model evaluates macro economic impacts. It can be classified as a multi-sectors, multi-regions, recursive dynamic CGE model that covers 22 economic commodities and corresponding sectors. It could capture the full range of interaction and feedback effects between different components in the economic system, which provides a more systematic estimation on measuring the economic impact of air pollutions. The results of work time loss from this health model are inputs as disturbance variables to the CGE model so that macroeconomic impacts can be simulated. It also allows the comparison and quantification of different impacts from different scenarios. More details of this IMED/CGE model could be found in our previous studies (Tian et al., 2018; Wu et al., 2017; Xie et al., 2016). In addition, The BaU scenario in this CGE model assumes that the health impacts from $\mathrm{PM}_{2.5}$ pollution are ignored. The socio-economic assumptions in China can be found in Supporting Information (SI)-Table S1.

\section{Results}

\subsection{The role of road transport sector toward the 2-degree target}

Table 2 shows the effects of climate change mitigation on emissions reduction of all sectors under the 2DEG_all scenario and the road transport sector alone under the 
2DEG_RT scenario in 2050, as well as the corresponding health and economic impacts. For the whole China, due to the reduction of energy consumption, the climate policy toward the 2-degree target would lead to 11.9 million ton (Mt) of $\mathrm{NO}_{\mathrm{X}}, 3.0 \mathrm{Mt}$ of $\mathrm{PM}_{2.5}$, 12.4 Mt of $\mathrm{SO}_{2}$, and $12493.3 \mathrm{Mt}$ of $\mathrm{CO}_{2}$ emissions reduction. In terms of air quality improvement, the $\mathrm{PM}_{2.5}$ concentration would be reduced by $23.5 \mathrm{ug} / \mathrm{m}^{3}$ in 2050 . Consequently, the health indicators would improve significantly. For instance, mortality would be reduced by 837.1 thousand, morbidity risk would be reduced by $2.0 \%, 31.5$ billion USD (B.USD) of additional expenditure would be saved, per capital work time loss would be lowered by 4.0 hours, and 582.3 B.USD of MEEV would be recovered. As a whole, after achieving the 2-degree target, the whole country would gain 613.8 B.USD (about $4.2 \%$ of GDP) in 2050.

When the climate change mitigation strategy is only implemented in the road transport sector, the above indicators will decrease as well. By comparing the reductions in the 2DEG_RT scenario with those in the 2DEG_all scenario in which all sectors cut emissions, the contribution of the road transport sector could be distinguished. For instance, $20.9 \%$ of $\mathrm{NO}_{\mathrm{X}}$ emission reduction (2.5 instead of $11.9 \mathrm{Mt}$ ) could be attributable to road transport sector. Similarly, climate actions in this sector account for $7.6 \%$ of total $\mathrm{PM}_{2.5}$ emission reductions, $0.4 \%$ of total $\mathrm{SO}_{2}$ reductions, $5.4 \%$ of total $\mathrm{CO}_{2}$ reductions and $10.6 \%$ of $\mathrm{PM}_{2.5}$ reduction . As a result, among all health benefits due to climate change mitigation, $10.7 \%$ of mortality, $10.8 \%$ of morbidity, $11.0 \%$ of additional expenditure, $8.7 \%$ of work time loss, and $10.7 \%$ of MEEV are attributable to the road transport sector. By using VSL and Cost of Illness (COI) approaches, the 
economic benefit is equivalent to $10.8 \%$ of the whole China's economic gain.

\begin{tabular}{llll}
\hline Items & 2DEG_all & $\begin{array}{c}2 \mathrm{DEG} R \mathrm{RT} \\
(\%)\end{array}$ \\
\hline \multicolumn{4}{c}{ Emission (Mt) and $\mathrm{PM}_{2.5}$ concentration $\left(\mathrm{ug} / \mathrm{m}^{3}\right)$ reduction } \\
\hline $\mathrm{NO}_{\mathrm{X}}$ & 11.9 & 2.5 & $20.9 \%$ \\
$\mathrm{PM}_{2.5}$ & 3.0 & 0.9 & $7.6 \%$ \\
$\mathrm{SO}_{2}$ & 12.4 & 0.1 & $0.4 \%$ \\
$\mathrm{CO}_{2}$ & 12493.3 & 677.6 & $5.4 \%$ \\
$\mathrm{PM}_{2.5}$ concentration & 23.5 & 2.5 & $10.6 \%$ \\
\hline \multicolumn{4}{c}{ Health impacts reduction } \\
\hline Mortality (Thousand deaths) & 837.1 & 90.0 & $10.7 \%$ \\
Morbidity (\%) & $2.0 \%$ & $0.2 \%$ & $10.8 \%$ \\
Expenditure (Billion USD) & 31.5 & 3.5 & $11.0 \%$ \\
Work time loss (Per capital- & 4.0 & 0.3 & $8.7 \%$ \\
hours) & \multicolumn{3}{|c}{} \\
MEEV (Billion USD) & 582.3 & 62.5 & $10.7 \%$ \\
\hline
\end{tabular}

Economic impacts reduction (Billion USD)

\begin{tabular}{llll}
\hline Benefit & 613.8 & 66 & $10.8 \%$ \\
\hline
\end{tabular}

3.2. The impact of road transport sector toward the 2-degree target at the provincial level

\subsubsection{Emissions and additional $P M_{2.5}$ concentration}

Figure 2 shows the reduction of emission and $\mathrm{PM}_{2.5}$ concentration under climate change mitigation at the provincial level in 2050. In accordance with energy consumption saving in each province in 2050 , the emissions would also be reduced. For instance, the

313 climate change mitigation effort will bring the highest reduction in $\mathrm{NO}_{\mathrm{x}}, \mathrm{SO}_{2}$, and $314 \mathrm{PM}_{2.5}$ emissions in those populous regions which are more dependent on industries such 315 as Shandong, Guangdong, Jiangsu, Hebei and Henan provinces. On the other hand, 316 those provinces with less population or less developed industries such as Ningxia, 
317 Qinghai and Shaanxi provinces have the lowest emission reduction.

319 Emissions reduction could further lead to the reduction of $\mathrm{PM}_{2.5}$ concentrations.

320 Compared with REF scenario, $\mathrm{PM}_{2.5}$ concentration would decrease by around $1.3 \%$ -

$3216.0 \%$ in most provinces. The top reduction provinces mainly locate in central and

322 eastern China, such as Henan (reduction by $5.6 \%$, or $4.6 \mathrm{ug} / \mathrm{m}^{3}$ ), Anhui (by $5.8 \%$, or

$3234.4 \mathrm{ug} / \mathrm{m}^{3}$ ), Hunan (by $5.5 \%$, or $4.3 \mathrm{ug} / \mathrm{m}^{3}$ ), Shanghai (by $6.0 \%$, or $4.2 \mathrm{ug} / \mathrm{m}^{3}$ ) and Hubei

324 (by $5.0 \%$, or $3.9 \mathrm{ug} / \mathrm{m}^{3}$ ). By contrast, provinces such as Hainan (by $1.7 \%$, or $0.3 \mathrm{ug} / \mathrm{m}^{3}$ ),

325 Yunnan (by $1.3 \%$, or $0.4 \mathrm{ug} / \mathrm{m}^{3}$ ) and Qinghai (by $3.2 \%$, or $0.5 \mathrm{ug} / \mathrm{m}^{3}$ ) would experience

326 lower reduction. 

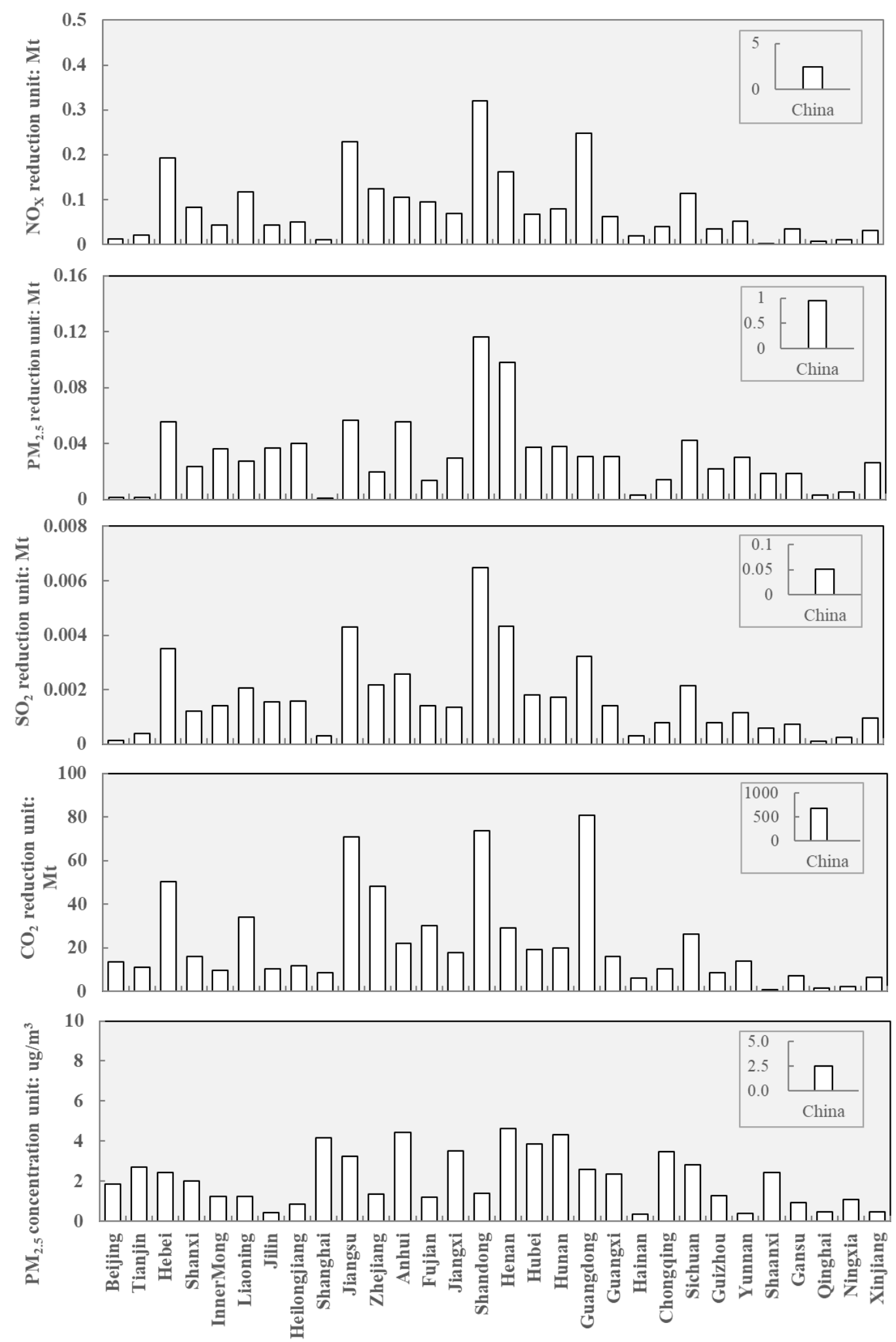

Figure 2 The emission and $\mathrm{PM}_{2.5}$ concentration reductions under climate change mitigation in 2050 
Exposure to a high level of $\mathrm{PM}_{2.5}$ concentrations could increase the risk of suffering from $\mathrm{PM}_{2.5}$ pollution-related health problems. The implementation of climate change mitigation under the 2DEG_RT scenario could reduce the number of patients by around $2.0 \%-45.5 \%$ in most provinces, and the provinces with a higher reduction in $\mathrm{PM}_{2.5}$ concentration would avoid more health loss. For instance, Henan would avoid annual mortality by 12.4 thousand people, while Hainan would only avoid 0.07 thousand of annual mortality.

The health problem caused by $\mathrm{PM}_{2.5}$ pollution would lead to additional health expenditure, the magnitude of which depends on climate change mitigation, income level and medical facility level in different provinces. The top provinces with the most reduction of extra medical expenditures under the 2DEG_RT scenario are Sichuan, Hunan, Hubei and Anhui, decreased by 54.2 Million USD (M.USD), 45.0 M.USD, 36.8 M.USD and 42.8 M.USD, respectively, equivalent to $0.01 \%$ of their GDPs.

In terms of mortality risk reduction after climate change mitigation, avoided MEEV loss would be more in Henan and Hunan provinces which have the most $\mathrm{PM}_{2.5}$ pollutant reductions. Besides that, high-income and more developed provinces such as Jiangsu and Guangdong would also avoid more MEEV loss. It is probable that with better quality of life, people would pay more attention to health effects. Meanwhile, investment for environmental improvement in developed regions would bring substantial benefits to their residents. 
$355 \mathrm{PM}_{2.5}$ concentration reduction could also reduce people's work time loss. Provinces

356 with high morbidity and mortality reduction such as Henan, Anhui, Hunan, Shanghai

357 and Hubei would reduce their work time loss. The per capital work time loss in these

358 provinces would be reduced by $6.0,4.9,4.1,5.0$ and 4.0 hours under the 2DEG_RT

359 scenario, respectively.

360 


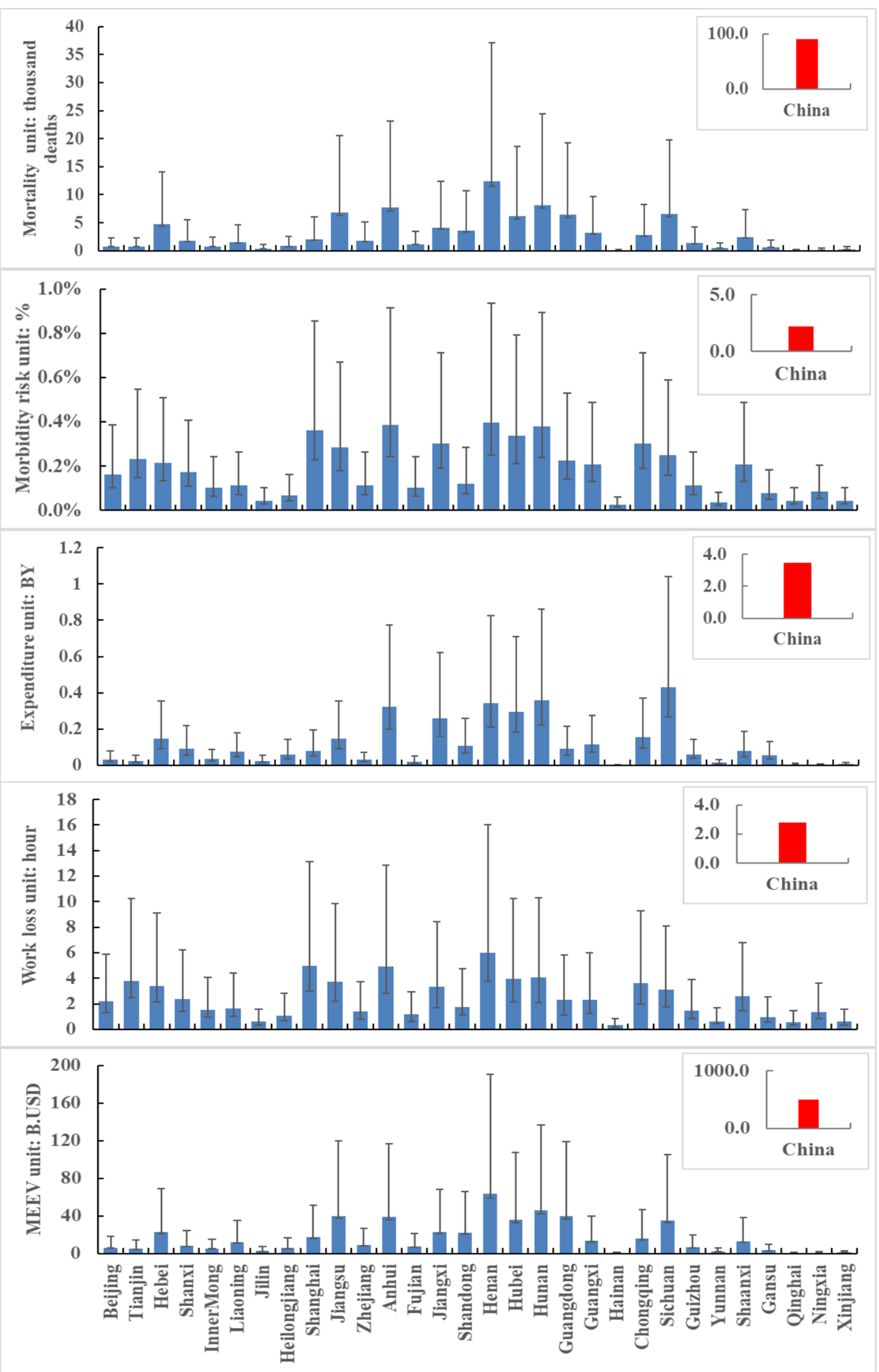

Figure 3 The health and economic effects after climate change mitigation in 2050 


\subsection{The co-benefits brought by climate change mitigation}

In order to reduce air pollutants from the road transport sector, one effective measure is to upgrade vehicle technologies. In our previous study (Tian et al., 2018), we explored the health and economic impacts only from technology upgrade. In order to identify the co-benefits brought by climate change mitigation, we take technology upgrade control under the TECH scenario as a benchmark in road transport sector. After compared the $\mathrm{PM}_{2.5}$ pollutant impact, the related health impacts and economic impacts under the 2DEG_RT scenario to these impacts under the TECH scenario, the co-benefits brought by climate change mitigation can be identified. The results at both national and provincial levels are shown in SI-Figure S1 and Figure S2.

At national level, $72.7 \%$ of the $\mathrm{PM}_{2.5}$ reduction could be achieved by climate actions under the 2DEG_RT scenario. Accordingly, $72.9 \%$ of avoided morbidity and mortality, $88.0 \%$ of reduced work time loss, $68.9 \%$ of saved extra expenditure, and $73.7 \%$ of lowered MEEV could be realized under the 2DEG_RT scenario, indicating that climate actions could bring significant synergies in cleaning air pollution resulted from the road transport sector.

The co-benefits brought by climate change mitigation are significantly different at provincial level. For the $\mathrm{PM}_{2.5}$ pollutant and health indicators, around 36\% provinces (such as Beijing and Shanghai) show that they gain more benefits under the 2DEG_RT scenario than those under the TECH scenario. The main reason is due to the limited improvement space by air pollution-oriented technology upgrade in these more developed provinces. In the past, different provinces had different enforcement on 
vehicle emission standards. In megacities such as Shanghai and Beijing, both vehicle emission standards and monitoring capacities are much higher than other provinces,

388 indicating that vehicles in such megacities are more efficient than those in the central 389 and western provinces and their environmental and health impacts are relatively lower 390 (Wu et al., 2016). Therefore, climate change mitigation would bring more additional space for Shanghai and Beijing to address their air pollutant issues from the road

392 transport sector. By contrast, for most central and western provinces, the 393 implementation of climate change mitigation would bring around $48 \%-90 \% \mathrm{PM}_{2.5}$ 394 pollutant and health co-benefits compared to the implementation of technology upgrade. maximized embodied economic value (MEEV) gains) after the implementation of climate or air pollution control measures are shown in Figure 4. It is clear that economic trends are similar to the pollutant and health trends. 


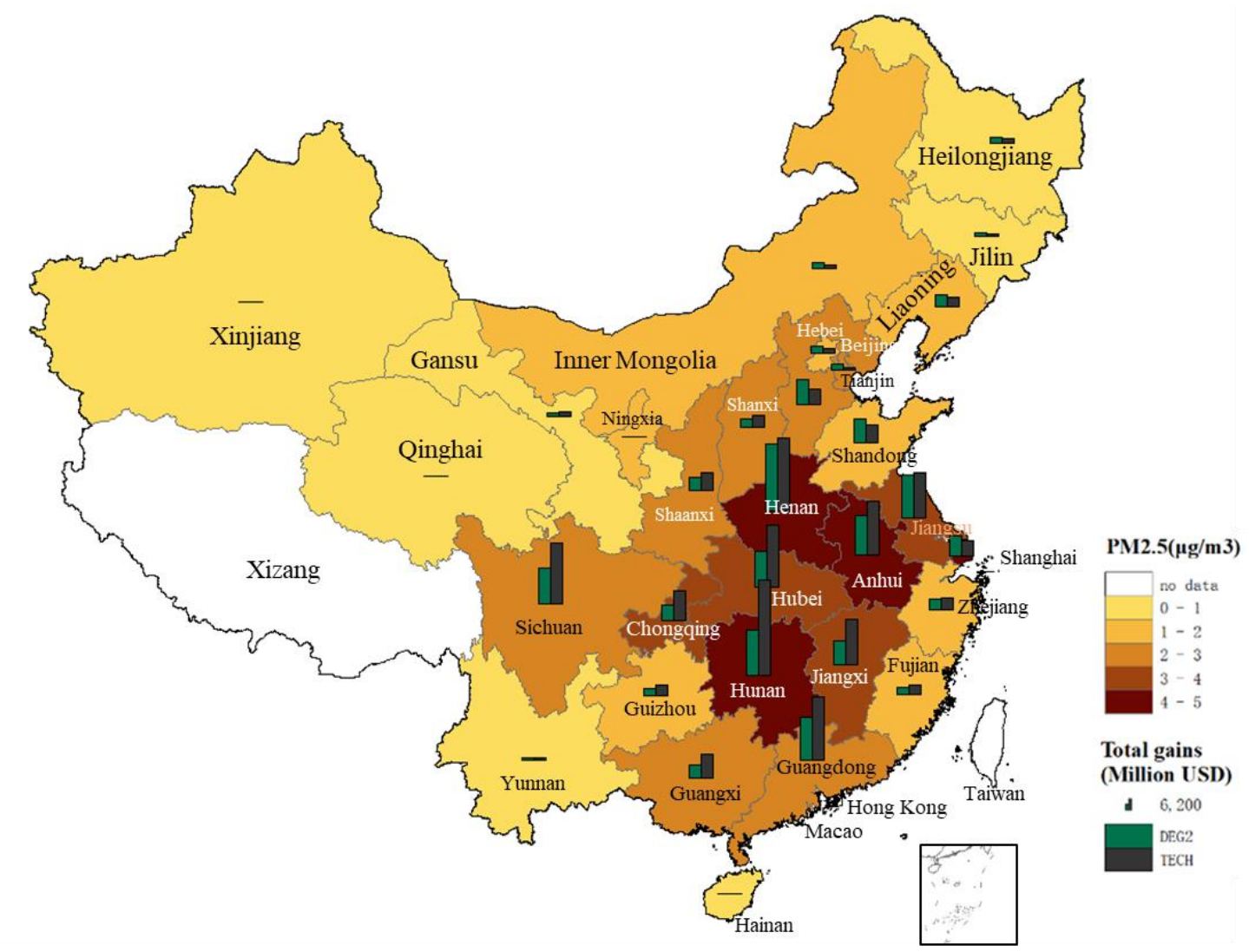

Figure 4 The provincial economic benefits from climate and air pollution control actions (The background color represents the concentration of $\mathrm{PM}_{2.5}$ and the column represents economic benefits under different scenarios)

\section{Discussions}

\subsection{Policy implications}

Our study confirms that China's road transport sector could contribute to around $10.6 \%$ of total $\mathrm{PM}_{2.5}$ concentration reduction resulted from all sectors' participation, equivalent to $10.8 \%$ of the monetized health benefits obtained from achieving the 2 degree target by all sectors. Furthermore, compared with the potential maximum benefits from air pollution control oriented measures in the road transport sector, such climate actions could bring noticeable synergies as well. For instance, $70 \%$ of avoided 
negative health impacts by air pollution control measures could be obtained by taking climate change mitigation actions alone. Therefore, it is beneficial for the road transportation sector to achieve the emissions reductions required by the 2 degree target climate change mitigation.

According to our scenarios, China's road transport sector toward the 2 degree target would be effected by energy consumption. The major character is that although oil is still the most important energy source, the proportion of electricity, natural gas and biofuels will increase significantly in the future. Therefore, ambitions of making such energy consumption transition in China's road transport sector at provincial level become more important.

For local government. It is necessary to integrate the road transport sector towards the 2 degree target into provincial planning, enhancing the awareness of different stakeholders to achieve such a target. For instance, the quality of road transport infrastructure is different at provincial level. Poor infrastructure quality would increase the corresponding emissions. Therefore, local government should reinforce the construction and maintenance of infrastructure, improving the transportation efficiency of vehicles via advanced communication and information technology, especially in provinces with populous and dense industries.

The electric vehicle-led road transportation system will be the future development trend toward the 2 degree target. Provinces should consider preparing medium- and long-term plan for the development of electric vehicles. For instance, for less developed provinces with low usage of electric vehicles, local government should increase the 
usage via intensifying financial subsidy. Besides that, the related infrastructure such as charging pile and charging service capacities should be consistent with the increasing demand of electric vehicles. The good experience in Chongqing is that owners of new energy electric vehicles can receive subsidies ranging from 10,000 RMB to 30,000 RMB from the local government. In addition, local government may consider the exemption of tolls for new energy electric vehicles (IEA, 2017).

Sharing economy could provide another solution for decreasing energy consumption in road transport. It is reported that per sharing car from Gofun company could reduce 30 ton emissions from vehicles per year ${ }^{1}$. Local government should encourage residents to use sharing electrical cars or sharing bikes instead of private cars through innovative policies. For instance, individuals may be granted with personal credits for their low carbon behaviors. Also, to increase parking fee and highway toll can also discourage the public to drive their own vehicles.

Upgrade of vehicle emission standards and fuel quality are required especially in central and western provinces. In the past few years, China's manufacturing industry has gradually transferred from eastern provinces to central and western provinces. Such shifts could bring certain economic benefits to these provinces, such as income growth and job opportunities. However, our analysis results indicate that there will be additional environmental burdens due to the increasing road transport loads. From the consumption perspective, taking Henan province as an example, it is reported that the total number of vehicles has increased significantly, leading to increasing emissions

\footnotetext{
http://www. tanpaifang. com/ditanjing ji/2017/0824/60378. html 
from road transport sector. However, as one central province, Henan's vehicle emission standards are lower than those in eastern provinces and the road transport infrastructure is less efficient. Therefore, it is of utmost importance to promote both vehicle emission standards and fuel quality. In this regard, Guangzhou province has decided to replace all their gasoline or diesel based buses by pure electric buses by the end of 2020 (IEA, 2017).

For residents. It is critical to encourage all the citizens to take public transport system, such as buses, subways, and ferries. Similarly, the smart monitoring system should be established so that the emissions from vehicles can be better monitored. In addition, it would be necessary to encourage the general public to take the sharing bikes or even walk for short distance travel.

In addition, it is worth noting that emissions could be influenced by long-range atmospheric transport and chemistry effects. For instance, Sichuan is located in the Sichuan Basin, where it is quite difficult for the air pollutants to disperse. Consequently, it is crucial for different provinces to take co-control strategies to maximize the cobenefits of emissions reduction and health impacts (Wu et al., 2017).

\subsection{Uncertainty Analysis}

Uncertainty analysis on ERFs used in the health model is carried out in this study, the error bars in Figure 3 show 95\% CI of ERFs. We use the high and low values of each indicator compared with their medium value. The risk of morbidity ranges between $63 \%$ and $36 \%$, mortality between $-93 \%$ and $100 \%$, expenditure between $-62 \%$ and $41 \%$, 
MEEV between $-93 \%$ and $100 \%$, and work time loss between $-58 \%$ and $62 \%$ under the 2DEG_RT scenario, indicating that chronic mortality and MEEV caused by ambient air pollution are sensitive to ERFs. Nonetheless, only $2 \%$ of work time loss will result from mortality so that the sensitive and variable mortality is not likely to influence the economic results considerably.

\subsection{Limitations}

Several research limitations exist and need to be improved in the future. For instance, this study does not provide detailed abatement costs due to limited data availability. Also, this study only focuses on the road transport sector rather than looking at all transport modes due to limited data availability in the shipping and air transport sectors. Further, this study does not investigate more co-benefits combing these two transport sectors. In this current study, we did not consider non-road transport modes (such as railway) due to the rough structure of our model. Under such a circumstance, our results may underestimate the co-benefits from the 2-degree target measures. Take residential vehicles as an example, if more residents select subway as one transport tool instead of private cars, reduction of $\mathrm{PM}_{2.5}$ concentration would be more obvious. Therefore, the health benefits would be more significant.

Finally, we did not identify the impacts of different specific measures, such as transitions to e-mobility. The work time loss could be underestimated in this study if only considering work loss hour while ignoring the impacts on productivity. This is because it is difficult to quantify the impact on labor productivity under the current 
technology.

\section{Conclusions}

The contribution of the road transport sector to co-benefits of achieving the 2-degree target at national and provincial levels in China is evaluated by combining the GAINS, IMED/HEL and IMED/CGE models. The main purpose of this study is to reveal the role of China's road transport sector toward the 2-degree target in 2050 and the synergies in creating public health co-benefits due to air pollution improvement. The results show that compared with the total emissions reduction from all sectors required by the 2-degree target, reductions from the road transport sector would account for $20.9 \%$ contributing to $10.6 \%$ of the total decrease. Furthermore, in terms of health impacts, the road transport sector could contribute to around $10.7 \%$ of decline in mortality and achieve more health impacts under the 2-degree target. Both economic development 
change mitigation.

Finally, this study confirms that mitigation efforts by China's road transport sector toward the 2-degree target could achieve significant co-benefits on air pollution improvement in the long run. Climate change mitigation can contribute to around $70 \%$ of the maximum health co-benefits obtained from air pollution control. With this regard, attaining the 2-degree target can help air pollution control avoid approximately $70 \%$ economic loss. In addition, those provinces which suffer more health impacts from the road transport sector (such as Henan and Sichuan) will gain more benefits after the implementation of control measures, which further confirms the necessity of control measures in the road transport sector.

All of these contributions have valuable implications to other countries, especially those emerging economies or those reluctant to engage in climate actions. With China being the leader for a global 'green shift' (Mathews, 2017), more simulation studies should be initiated so that more mitigation strategies and policies can be raised by considering the local concerns.

\section{References}

Amann, M., Bertok, I., Borken, J., et al., 2008. GAINS ASIA. A tool to combat air pollution and climate change simultaneously. Methodology. (http://gains.iiasa.ac.at).

Andersson, H., Treich, N., 2011. The value of a statistical life. A handbook of transport economics $1-36$.

Berntsen, T., Fuglestvedt, J., 2008. Global Temperature Responses to Current Emissions from the Transport Sectors. P. Natl. Acad. Sci. USA 105, 19154-19159, PMID: 19047640, https://doi.org/ 
Cai, S., Wang, Y., Zhao, B., Wang, S., Chang, X., Hao, J., 2017. The impact of the "Air Pollution

Prevention and Control Action Plan" on $\mathrm{PM}_{2.5}$ concentrations in Jing-Jin-Ji region during 2012-

Sci. Total.

Environ. 580,

197-209,

PMID:

28011024 , https://doi.org/10.1016/j.scitotenv.2016.11.188.

Dai, Y., Kang, Y., Xiong, X., 2017. Energy development and carbon emission scenarios towards 2050. China Environmental Science Press, Beijing.

Dong, H., Dai, H., Liang, D., Fujita, T., Geng, Y., Klimont, Z., Inoue, T., Bunya, S., Fujii, M., Masui, T., 2015. Pursuing air pollutant co-benefits of $\mathrm{CO}_{2}$ mitigation in China: A provincial leveled analysis. Appl. Energ. 144, 165-174, https://doi.org/10.1016/j.apenergy.2015.02.020.

Dong, L., Liang, H., 2014. Spatial analysis on China's regional air pollutants and $\mathrm{CO}_{2}$ emissions: emission pattern and regional disparity. Atmos. Environ. 92, 280-291, https://doi.org/10.1016/j.atmosenv.2014.04.032.

Hanaoka, T., Masui, T., 2017. Exploring the $2{ }^{\circ} \mathrm{C}$ Target Scenarios by Considering Climate Benefits and Health Benefits-Role of Biomass and CCS. Energy Procedia 114, 2618-2630, https://doi.org/10.1016/j.egypro.2017.03.1424.

He, K., Lei, Y., Pan, X., Zhang, Y., Zhang, Q., Chen, D., 2010. Co-benefits from energy policies in China. Energy 35, 4265-4272, https://doi.org/10.1016/j.energy.2008.07.021. He, L.Y., Qiu, L.Y., 2016. Transport demand, harmful emissions, environment and health cobenefits in China. Energ. Policy 97, 267-275, https://doi.org/10.1016/j.enpol.2016.07.037.

IEA., 2016. International Energy Agency. World Energy Outlook. ISBN Print: 978-92-64-26494-6. 
responsibility of the Petroleum Industry Press.

Künzli, N., Kaiser, R., Medina, S., Studnicka, M., Chanel, O., Filliger, P., Herry, M., Horak, F., Puybonnieux-Texier, V., Quénel, P., Schneider, J., Seethaler, R., Vergnaud, J.H.S., 2000. Publichealth impact of outdoor and traffic-related air pollution: a European assessment. The Lancet 356, 795-801, https://doi.org/10.1016/S0140-6736(00)02653-2.

Lanzi, E., Dellink, R., Chateau, J., 2018. The sectoral and regional economic consequences of outdoor air pollution to 2060. Energ. Econ. 71, 89-113, https://doi.org/10.1016/j.eneco.2018.01.014. Lelieveld, J., Evans, J.S., Fnais, M., Giannadaki, D., Pozzer, A., 2015. The contribution of outdoor air pollution sources to premature mortality on a global scale. Nature 525, 367-371, PMID: 26381985, https://doi.org/10.1038/nature15371.

Li, X., Qiao, Y., Shi, L., 2017. The aggregate effect of air pollution regulation on $\mathrm{CO}_{2}$ mitigation in China's manufacturing industry: An econometric analysis. J. Clean. Prod. 142, 976-984, https://doi.org/10.1016/j.jclepro.2016.03.015.

Liang, Q.M., Deng, H.M., Liu, M., 2016. Co-control of $\mathrm{CO}_{2}$ emissions and local pollutants in China: the perspective of adjusting final use behaviors. J. Clean. Prod. 131, 198-208, https://doi.org/10.1016/j.jclepro.2016.05.048.

Liu, L., Wang, K., Wang, S., Zhang, R., Tang, X., 2018. Assessing energy consumption, $\mathrm{CO}_{2}$ and pollutant emissions and health benefits from China's transport sector through 2050. Energ. Policy 116, 382-396, https://doi.org/10.1016/j.enpol.2018.02.019.

Liu, Z., Mao, X., Tu, J., Jaccard, M., 2014. A comparative assessment of economic-incentive and command-and-control instruments for air pollution and $\mathrm{CO}_{2}$ control in China's iron and steel sector.

J. Environ. Manage. 144, 135-142, https://doi.org/10.1016/j.jenvman.2014.05.031. 
Mathews, J.A., 2017. Global Green Shift: When Ceres Meets Gaia. Anthem Press.

Mao, X., Yang, S., Liu, Q., Tu, J., Jaccard, M., 2012. Achieving $\mathrm{CO}_{2}$ emission reduction and the cobenefits of local air pollution abatement in the transportation sector of China. Environ. Sci. Policy 21, 1-13, https://doi.org/10.1016/j.envsci.2012.03.010.

Meng, J., Liu, J., Xu, Y., Tao, S., 2015. Tracing Primary PM$_{2.5}$ emissions via Chinese supply chains. Environ. Res. Lett. 10, 1-12, https://doi.org/10.1088/1748-9326/10/5/054005.

Nam, K.M., Waugh, C.J., Paltsev, S., Reilly, J.M., Karplus, V.J., 2013. Carbon co-benefits of tighter $\mathrm{SO}_{2}$ and $\mathrm{NO}_{x}$ regulations in China. Global Environ. Chang. 23, 1648-1661, https://doi.org/10.1016/j.gloenvcha.2013.09.003.

Pan, L., Yao, E., Yang, Y., 2016. Impact analysis of traffic-related air pollution based on real-time traffic and basic meteorological information. J. Environ. Manage. 183, 510-520, https://doi.org/10.1016/j.jenvman.2016.09.010.

Peng, W., Yang, J., Lu, X., Mauzerall, D.L., 2018. Potential Co-benefits of Electrification for Air quality, Health, and $\mathrm{CO}_{2}$ Mitigation in 2030 China. Appl. Energ. 218, 511-519, https://doi.org/10.1016/j.apenergy.2018.02.048.

Takeshita, T., 2012. Assessing the co-benefits of $\mathrm{CO}_{2}$ mitigation on air pollutants emissions from road vehicles. Appl. Energ. 97, 225-237, https://doi.org/10.1016/j.apenergy.2011.12.029.

Tian, X., Dai, H., Geng, Y., Wilson, J., Wu, R., Xie, Y., Hao, H., 2018. Economic impacts from $\mathrm{PM}_{2.5}$ pollution-related health effects in China's road transport sector: A provincial-level analysis. Environ. Int. 115, 220-229, https://doi.org/10.1016/j.envint.2018.03.030.

UNFCCC (United Nations Climate Change),, 2018. https://unfecc.int/process/the-parisagreement/what-is-the-paris-agreement (accessed June 30, 2018). 
610

611

612

613

614

615

616

617

618

619

620

621

622

623

624

625

626

627

Watts N., Amann M., Arnell N., et al., 2018. The 2018 report of the Lancet Countdown on health and climate change: shaping the health of nations for centuries to come. The Lancet 392 (10163), 2479-2514, https://doi.org/10.1016/S0140-6736(18)32594-7.

Wu, R., Dai, H., Geng, Y., Xie, Y., Masui, T., Liu, Z., Qian, Y., 2017. Economic Impacts from $\mathrm{PM}_{2.5}$ Pollution-Related Health Effect: A Case Study in Shanghai. Environ. Sci. Tech. 51, 5035-5042, https://doi.org/10.1021/acs.est.7b00026.

Wu, X., Wu, Y., Zhang, S., Liu, H., Fu, L., Hao, J., 2016. Assessment of vehicle emission programs in China during 1998-2013: Achievement, challenges and implications. Environ. Pollut. 214, 556567, https://doi.org/10.1016/j.envpol.2016.04.042.

Xia, X.H., Hu, Y., Chen, G.Q., Alsaedi, A., Hayat, T., Wu, X.D., 2015. Vertical specialization, global trade and energy consumption for an urban economy: A value added export perspective for Beijing. Ecol. Model. 318, 49-58, https://doi.org/10.1016/j.ecolmodel.2014.11.005.

Xie, Y., Dai, H., Dong, H., Hanaoka, T., Masui, T., 2016. Economic impacts from $\mathrm{PM}_{2.5}$ pollutionrelated health effects in China: A provincial-level analysis. Environ. Sci. Tech. 50, 4836-4843, https://doi.org/10.1021/acs.est.5b05576.

Xie, Y., Dai, H., Xu, X., Fujimori, S., Hasegawa, T., Yi, K., Masui, T., Kurata, G., 2018. Co-benefits of climate mitigation on air quality and human health in Asian countries. Environ. Int. 119, 309-318, https://doi.org/10.1016/j.envint.2018.07.008.

Yan, X., Crookes, R.J., 2010. Energy demand and emissions from road transportation vehicles in China. Prog. Energ. Combust. 36, 651-676, https://doi.org/10.1016/j.pecs.2010.02.003.

Zhang, Z.H., Khlystov, A., Norford, L.K., Tan, Z.K., Balasubramanian, R., 2017. Characterization of traffic-related ambient fine particulate matter $\left(\mathrm{PM}_{2.5}\right)$ in an Asian city: Environmental and health 
632 implications. Atmos. Environ. 161, 132-143, https://doi.org/10.1016/j.atmosenv.2017.04.040.

633 